\begin{tabular}{|c|c|}
\hline hommes & $\begin{array}{l}\text { Hommes \& migrations } \\
\text { Revue française de référence sur les dynamiques } \\
\text { migratoires } \\
\mathbf{1 2 8 1} \text { | } \mathbf{2 0 0 9} \\
\text { France-Brésil sous l'angle des migrations et de } \\
\text { l'altérité }\end{array}$ \\
\hline \multicolumn{2}{|c|}{ Les mémoires d'un père en héritage } \\
\hline \multicolumn{2}{|c|}{$\begin{array}{l}\text { OpenEdition } \\
\text { Journals }\end{array}$} \\
\hline \multicolumn{2}{|c|}{$\begin{array}{l}\text { Édition électronique } \\
\text { URL : http://journals.openedition.org/hommesmigrations/404 } \\
\text { DOI : } 10.4000 / \text { hommesmigrations. } 404 \\
\text { ISSN : 2262-3353 }\end{array}$} \\
\hline \multicolumn{2}{|c|}{$\begin{array}{l}\text { Éditeur } \\
\text { Musée national de l'histoire de l'immigration }\end{array}$} \\
\hline \multicolumn{2}{|c|}{$\begin{array}{l}\text { Édition imprimée } \\
\text { Date de publication : } 1 \text { septembre } 2009 \\
\text { Pagination : } 174-179 \\
\text { ISSN : } 1142-852 X\end{array}$} \\
\hline $\begin{array}{l}\text { Référence électroniq } \\
\text { Fabrice Grognet, « Les } \\
\text { mis en ligne le } 29 \text { mai } \\
\text { hommesmigrations/4 }\end{array}$ & $\begin{array}{l}\text { némoires d'un père en héritage », Hommes \& migrations [En ligne], } 1281 \text { | 2009, } \\
013 \text {, consulté le } 22 \text { septembre 2020. URL: http://journals.openedition.org/ } \\
4 \text {; DOI : https://doi.org/10.4000/hommesmigrations.404 }\end{array}$ \\
\hline
\end{tabular}

Ce document a été généré automatiquement le 22 septembre 2020.

Tous droits réservés 


\title{
Les mémoires d'un père en héritage
}

\author{
Fabrice Grognet
}

1 À la fin de l'année 2007, après avoir visité la Cité nationale de l'histoire de l'immigration, Jacques Bedrossian - accompagné de son cousin Pierre Mampreyan ${ }^{1}$ propose d'évoquer la vie de son père, Arménien venu de Cilicie, à partir de documents devant faire l'objet d'un don au musée.

\section{Sur les traces d'une histoire familiale et d'une mémoire d'exil}

2 Cette initiative vient, en quelque sorte, conclure une démarche entamée par les deux cousins autour de la vie de leurs parents respectifs :

\footnotetext{
"On a eu un peu un rejet de toute cette histoire pendant notre adolescence et même pendant notre vie professionnelle. Et c'est revenu après-coup, quand nos parents ont disparu", explique Jacques Bedrossian.

"Les parents étant là, la mémoire était là, ce n'était pas important que l'on s'en occupe. Mais après, on n'entendait plus parler de ceci, plus parler de cela... C'est là où on a pris la relève en quelque sorte. Et on regrette énormément de ne pas avoir fait connaître à nos parents ce que l'on fait aujourd'hui. C'est devenu un hommage posthume."
}

3 Tribut aux parents disparus, retour vers les origines d'une famille et volonté de faire vivre et connaître une identité arménienne "déterritorialisée" ${ }^{2}$, tels sont les moteurs de cette démarche menant à un passé ravivé et aux vitrines du musée :

“Avant la retraite, on n'avait pas nécessairement le temps de rechercher dans le passé. Il fallait travailler, s'occuper de la famille... Bien entendu, il y avait les commémorations du 24 avril $^{3}$ qui avaient un peu engagé les choses. Et puis il y a eu aussi l'ASALA - l'Armée secrète arménienne de libération de l'Arménie - et l'attentat d'Orly'. C'est à partir de ce moment, à l'occasion de coups durs avec lesquels nous n'étions pas d'accord, que l'on a commencé à parler de tout cela dans la famille."

Retraité, Jacques Bedrossian part alors sur les traces de ses parents : 
“J'ai fait le Liban, là où étaient les parents à Grazir, la Syrie. Et j'ai fait aussi la Turquie de l'Est en 1992, là où vivaient nos parents. Comme c'était en voyage organisé, j'ai demandé à ce que le car passe à Marache. On m'a donné une demiheure pour me promener. J'ai essayé, à ma manière, sans connaître la langue, d'interroger des vieux Turcs, de savoir où était le quartier arménien. Ils m'ont fait comprendre qu'il n'y avait plus rien et que tous les Arméniens étaient partis en Syrie... Et pour cause ! D'après ce que j'ai compris, les quartiers ont été brûlés et il ne reste plus rien de ce qui était arménien à Marache."

Mais la démarche de Jacques, impliquant un retour sur la terre natale de ses parents, n'est pas toujours bien perçue par les autres enfants des rescapés du génocide :

“À l'époque, on m'a traité d'inconscient, parce que, dans le cœur des Arméniens, aller en Turquie, c'était tabou. On m'a dit : 'Tu vas donner de l'argent dans ce pays pour voyager alors qu'ils nous ont fait beaucoup de mal."”

6 Jacques et Pierre sont donc partis vers leurs racines arméniennes et ont fait de leurs recherches un devoir de transmission suivi par toute la famille :

“Je n'ai pas d'enfant. Mais tous les documents que j'ai pu réunir avec mon cousin Pierre - ont été dupliqués aux sœurs, aux frères, aux petits-enfants. Les objets qui étaient jusque-là disséminés dans la famille nous ont été envoyés ${ }^{5}$. On a fait en sorte de tout continuer. Et maintenant on attend - et toute la famille avec nous - que tout cela soit présenté au musée."

\section{Les "mémoires de papier" de Melkon Bedrossian (1906-1990)}

7 Melkon Bedrossian est né le 15 avril 1906 dans le village de Sarelar, au pied de la montagne Guéavour Dagh, en Cilicie (actuelle Turquie). Orphelin de père depuis les massacres de 1909, il fait partie de ces Arméniens contraints à l'exil pour fuir le génocide perpétré de 1915 à 1916 par le gouvernement des Jeunes Turcs de l'Empire ottoman, les accusant de collaboration avec l'ennemi russe de l'époque.

8 Soixante-trois ans plus tard, Melkon entreprend de rédiger les mémoires de cet exode sur un cahier d'écolier où est inscrit sobrement : "Bedrossian Melkon, 14 rue du Coteau, 92160 Antony.” Son fils, Jacques, traduit et dactylographie ce manuscrit rédigé dans la langue maternelle de Melkon et tient désormais à transmettre ce témoignage qui devient ainsi le support matériel de l'histoire de la famille :

"Un matin, la triste nouvelle arriva. Le décret était paru et une ordonnance lancée. Les Arméniens ${ }^{6}$ devaient quitter le village et prendre le chemin de la déportation dans un délai de huit heures, c'est-à-dire avant le soir. À cette période, notre père, victime des persécutions, avait laissé veuve ma jeune mère, et orphelins de père mes trois sœurs et moi-même. Nous étions dans l'embarras car le bétail était au champ, les chèvres et les moutons à paitre sur la montagne, nous ne pouvions rien récupérer ni vendre. Nous avons emmené tout ce que nous pouvions charger sur le cheval. Le strict nécessaire: quelques couvertures, habits et outres de peau de chèvre pour conserver l'eau. Nous aurions voulu emporter tant de choses!

Ce jour triste et noir, nous avons abandonné à la hâte jardins et maison. Notre caravane se composait de trois villages voisins, Sarelar, Kezel Aghay et Gueul Djeyiz. Dès lors, nous devenions apatrides, condamnés à la précarité et à l'errance, notre survie dépendrait de la charité, de l'hospitalité et de la chance. Notre souci, rester ensemble [...].

Direction Alep, en Syrie. Nous avons escaladé des montagnes et traversé des rivières. J'avais à peine dix ans, c'était un supplice mais il fallait continuer [...]. Arrivés à la frontière, à Eradjov, ce fut un miracle : je vis pour la première fois un 
gigantesque pont en fer qui reliait deux montagnes ainsi qu'un train [...]. Nous ne savions pas quels tristes jours nous attendaient. Nous avions la nostalgie de la vie de notre pays qui nous paraissait comme un paradis. Les gens affamés, assoiffés et malades mouraient tous les jours au bord des routes."

\section{“Liban et orphelinat d'Ayntoura"}

"Arrivés à Hama, tous les enfants furent rassemblés et leurs têtes rasées, puis ils furent séparés de leurs parents. Ma mère et ma grande sœur d'un côté, mes petites soeurs et moi d'un autre [...]. Le lendemain, nous avons pris le train pour le Liban. Après avoir traversé Baalbeck le soir, nous sommes arrivés à Rayat, où la ligne de chemin de fer se divisait en deux directions, l'une vers Damas, l'autre vers Beyrouth. Nous avons passé la nuit sous les tentes des soldats allemands et c'est ici que j'ai vu une automobile pour la première fois.

Le lendemain, départ vers Beyrouth, toujours par train, tellement lent qu'en escaladant la montagne un de nos camarades est descendu du train pour boire l'eau de la source qui se trouvait juste à côté de la voie et a repris le dernier wagon du train [...]. Notre destination finale était l'orphelinat d'Ayntoura, un ancien collège français à 25 kilomètres de Beyrouth. Après avoir été sélectionnés et numérotés, nous fûmes convertis de force à la religion musulmane. Désormais, mon nom était Négib, numéro 8, et mes sœurs furent rebaptisées l'une Aychée et l'autre Loutfia. C'était dur et humiliant, et nous pleurions souvent en pensant à notre maman, arrachée de nos bras à Hama. Tous les matins, la cloche nous réveillait les yeux rougis [...].

Les conditions dans cet orphelinat devenaient insupportables. En secret, je préparais chaque jour ma fuite en mesurant les conséquences au cas où je serais arrêté [...]. Un matin mémorable d'avril 1918, j'ai fait mes adieux à mes sœurs en larmes. Sans être aperçu, j'ai sauté par-dessus la grille et me suis dirigé vers Damas, via les montagnes du Liban et avec pour seul compagnon mon bâton d'exil, mille fois brisé et remplacé depuis [...]. Six mois après mon évasion, l'armée anglaise, aidée de légionnaires arméniens, a libéré l'orphelinat et capturé le personnel turc."

\section{La "mémoire vivante" d'un fils et d'une famille}

La suite de ce voyage irréversible de Melkon est racontée par son fils, Jacques :

“En 1921, mon père s'embarque pour la Grèce, destination Kavalla, où il travaille comme apprenti pour apprendre le métier d'ébéniste pendant deux ans. Sur ses papiers, il se fait rajeunir de deux ans afin de ne pas faire le service militaire grec."

Devenu "apatride" et interdit de séjour en Turquie (comme tous les rescapés du génocide) depuis le traité de Lausanne de 1923, Melkon apprend que la France recherche de la main- d'œuvre. En mars 1925, alors âgé de dix-sept ans, il prend le bateau pour Marseille avec un contrat d'embauche en poche. Comme tous les étrangers venant du bassin méditerranéen, Melkon doit alors être enregistré au Dépôt de travailleurs étrangers de Marseille. Tout d'abord affecté dans les Salines de Camargue,

“l'emploi ne correspond pas à son métier d'ébéniste. Un ami lui conseille d'aller à Valencienne, car il y a de l'emploi pour faire de la marqueterie sur les wagons de la SNCF. Il faut savoir qu'à cette époque on embauchait pour un travail et, une fois celui-ci terminé, on renvoyait. Mon père a ainsi fait beaucoup d'entreprises pour survivre".

11 Arrivé à Montreuil, “il travaille dur et met de l'argent de côté pour faire venir ses petites sœurs du Liban", sous mandat français depuis 1920. Mariam et Aravnie arrivent - enfin - en France en 1927. La famille retrouvée vit dans le même appartement et la vie s'organise. 
Les deux soeurs sont employées dans des usines de confiture à Boulogne. En 1929, alors que Melkon fait venir de l'orphelinat du Liban la surveillante et amie de ses sœurs, Anouche,

qui deviendra sa femme, Mariam et Aravni ${ }^{\text {e7 }}$ trouvent leurs conjoints respectifs dans la "communauté arménienne", constituée principalement des rescapés du génocide :

"Avant, l'objectif matrimonial, c'était de trouver une Arménienne pour un Arménien et un Arménien pour une Arménienne. Les Arméniens se retrouvaient très fréquemment entre immigrés quand ils étaient jeunes. Ils formaient une sorte de colonie, puisqu'ils habitaient tous la région parisienne, soit à Issy-lesMoulineaux, soit à Alfortville. Ils s'entraidaient et ils faisaient des petites fêtes, comme un bal annuel. Il y avait même une équipe de football. Ils ont créé des associations dans lesquelles ils se retrouvaient entre orphelins, car ils étaient presque tous orphelins".

Petit à petit, la vie se reconstruit :

"Ils recommencent à avoir un âge, un nom, un domicile. Les documents administratifs s'accumulent. Ce sont des trésors. Le premier souci de mon père a été de fabriquer un coffre digne de recevoir ces précieux documents, témoins de la renaissance de la famille. Ses premières soirées furent consacrées à fabriquer une boîte recouverte de marqueterie, à l'aide de morceaux de nacre et d'un plaquage de bois d'essences différentes."

14 Son décor reprend alors la cocarde du drapeau arménien et Melkon ajoute les initiales de sa femme, Anouche.

\section{Du statut de réfugié à celui de naturalisé}

Comme tous les apatrides résidant en France, Melkon est mobilisé en 1939, au moment où la guerre éclate :

"Le 2 septembre, mon père est mobilisé à Vannes, puis envoyé dans l'artillerie à Sedan. De là, il se rend par ses propres moyens à Agen, à la caserne Port-SainteMarie. Durant le trajet, il sera blessé au cours d'un mitraillage italien à Daussy dans l'Yonne."

Après la guerre, Melkon obtient la nationalité française :

"Mes parents se sont installés à Antony et ont eu trois enfants (Vahan, Jacques et Suzanne). Le rêve de mon père était de s'établir à son compte comme ébéniste. Mais cela n'a pu se faire et il a terminé sa carrière à "Antony Mobilier", à l'âge officiel de soixante-cinq ans - soixante-sept, en réalité.

Mon père ne retrouvera jamais la trace de sa mère ni de sa sœur aînée. Le cruel destin les avait peut-être placées sur la route du désert de Deir-es-Zor ${ }^{8}$."

\section{NOTES}

1. Lui aussi dans une démarche de don vis-à-vis de l'histoire de son père.

2. Martine Hovanessian, “L’identité arménienne”, Hommes et Migrations n 1158, 1992, p. 29. 
3. Le samedi 24 avril 1915, à Istanbul, capitale de l'Empire ottoman, 600 notables arméniens sont assassinés sur ordre du gouvernement. C'est le début d'un génocide, le premier du XXe siècle.

4. Attentat à la bombe perpétré à l'aéroport d'Orly, près du bureau de lignes aériennes turques, le 15 juillet 1983, qui a causé la mort de huit personnes.

5. "Mon oncle a toujours voulu symboliser les choses, pour chaque événement de sa vie. Il aimait faire des choses qui restent. Il a fait des tableaux, des portraits en marqueterie d'anciens rois d'Arménie", explique Pierre Mampreyan.

6. Principalement les femmes et les enfants, les hommes non mobilisés dans les rangs de l'armée ottomane étant très vite assassinés.

7. Aravnie se marie avec Hovhannes Azadian, mais celui-ci meurt pendant la guerre. En 1948, Aravnie se remarie avec Ovhannes Mampreyan. Ils auront un fils, Pierre.

8. Après des marches exténuantes durant lesquelles beaucoup d'entre eux meurent, nombre d'Arméniens sont déportés à Deir-es-Zor, dans le désert de Syrie, et exécutés.

\section{RÉSUMÉS}

“Avec mon faible vocabulaire, je ne peux décrire toutes les atrocités que j'ai vécues, d'ailleurs cela serait trop long. Et puis quel Arménien de mon pays n'a pas son histoire atroce ? Pourtant le récit des évènements que je raconterai est tellement imprégné dans ma mémoire et mon âme que je m'en souviens après soixante-trois ans. Et l'émotion m'étrangle toujours." Extrait des Mémoires de Melkon Bedrossian, le récit mouvementé de notre déportation de notre village en Turquie, 1905-1918.

\section{AUTEUR}

\section{FABRICE GROGNET}

Ethnologue, chargé de mission au Musée nationale de l'histoire et des cultures de l'immigration, CNHI 